\title{
Compulsão a Drogas - Um Olhar Existencial
}

\author{
Walmir dos Santos Monteiro \\ Universidade Severino Sombra, Pró-Reitoria de Pesquisa e Pós- \\ Graduação, Centro de Ciências da Saúde, Curso de Psicologia \\ monteiro.walmir@gmail.com
}

\begin{abstract}
Resumo: Neste artigo examinamos a questão da drogadicção à luz das dimensões da existência, segundo o fundamento fenomenologico-existencial. $O$ dependente químico estigmatizado e estereotipado como tem sido, comumente sofre com informações parciais e tendenciosas acerca de sua conduta e também é atingido por generalizações, faltando por parte da sociedade a devida atenção a aspectos fundamentais que envolvem variáveis sociais, econômicas, políticas e culturais, basilares à compreensão do fenômeno drogas. Aqui não nos detemos nessas variáveis, mas apresentamos a singularidade da visão existencial sobre a dependência química que seguramente serve como ponto de partida a uma análise mais profunda do tema.
\end{abstract}

Palavras-chave: Drogas. Dependência. Compulsão. Existencialismo. Terapia.

\section{DRUG ADDICTION: A VIEW FROM EXISTENTIAL}

\begin{abstract}
This article examines the issue of drug addiction in the dimensions of existence, according to the ground phenomenological-existential. The chemically dependent stereotyped and stigmatized as has been commonly suffers from partial and biased information about his conduct and is also touched by generalizations, lacking from society due attention to key issues that involve varying social, economic, political and cultural basic understanding of the drug phenomenon. Here you do not stop these variables, but the uniqueness of the present existential view about addiction that will surely serve as a starting point to a deeper analysis of the topic.
\end{abstract}

Keywords: Drugs. Dependence. Binge. Existencialism. Therapy. 


\section{Introdução}

Relembremos que a filosofia existencial fundamenta-se em quatro concepções básicas:

1) Uma ação é, por princípio, intencional;

2) A existência precede e comanda a essência;

3) Ser é fazer, ser é agir. Deixar de agir é deixar de ser.

4) Toda consciência é consciência de alguma coisa.

A modernidade foi construída e desenvolvida a partir da racionalidade grega e nossos modos de pensar e agir têm sido moldados por ela. A idéia de "conteúdos de consciência", de "interioridade da consciência" é uma delas.

Mas Sartre desafia o pensamento Aristotélico e propõe uma nova maneira de encarar a realidade. Diz ele "As aparições que manifestam o Existente não são interiores nem exteriores. A aparência não esconde a essência, mas a revela: ela é a essência".

Para Sartre, então,tudo está no ato, na escolha.

A visão de homem no existencialismo é a de alguém existindo sempre em movimento, agindo e sofrendo ações, desgastando e sendo desgastado pelo processo de existir. Existir sugere ser-para-fora (ex-sistere), ser-no-mundo. E esse movimento, esse desgaste, pode ser analisado consoante à consciência que persegue sempre e incansavelmente integração, consistência e coerência entre várias tendências, emoções, sentimentos e atitudes.

Talvez, paradoxalmente, o movimento compulsivo em direção às drogas seja uma tentativa de "existir", de "sair para fora", de transcender. Mas digo paradoxal porque é um movimento que trava querendo liberar, que retrocede querendo avançar. A droga é o paradoxo daquele que aspirando libertação, encontra-se com a escravidão. Porque as compulsões em geral operam a perda das rédeas da própria vida, resultando em uma certa "escravidão do hábito".

\section{Existencialismo e Drogadicção}

Diante do paciente drogadicto a existencial utiliza o conceito organísmico que diz que doença não é somente desequilíbrio ou desarmonia, mas, sobretudo, o esforço que a realidade humana exerce para obter um novo equilíbrio. O sujeito pode "escolher" a drogadicção para curar a si próprio, para alcançar um estado de equalização organísmica, o bem-estar do seu ser-no-mundo.

É um modo de captar o verdadeiro projeto de viver do paciente, a maneira de existir de uma certa pessoa, não se podendo extrair dessa análise um conjunto de avatares clínicos que venham a ser aplicados a outra pessoa, pois não é possível imaginar uma entidade chamada "pessoa" sem situá-la no mundo; e situar no mundo evoca "ação". 
É um método de investigação onde colocamos entre parênteses todo o conhecimento acerca do fenômeno e o visamos como ele é em si mesmo. A proposta da fenomenologia é uma volta "às coisas mesmas" como diria Husserl. E essa volta preza a valorização do manifesto, aquilo que aparece e não o que parece.

Porque o que parece é um exercício intuitivo e interpretativo da nossa consciência, um exercício noésico. Sartre diz que "a redução fenomenológica de Husserl propõe reduzir o mundo ao estado de correlato noemático da consciência“. Portanto, a fenomenologia é um método que faz mediação entre o sujeito e o objeto, entre o eu e a coisa.

$\mathrm{Na}$ fenomenologia, o conhecimento se dá na relação noesis-noema, duas expressões gregas que significam: Noesis: ato da consciência, disposição do sujeito para ver algo, modo de perceber e conhecer alguém. Noema: se mostra como o mundo que se dá a conhecer, o vivido, o experienciado.

Então, ou o indivíduo atribui significado através de algo que emerge intencionalmente à sua consciência ou busca o conhecimento no mundo que se mostra ou se deixa mostrar para ele. São, portanto, duas expressões husserlianas que definem dois pólos no processo de conhecimento ou investigação do fenômeno.

Quando Husserl trata da redução fenomenológica ressalta a necessidade de se colocar entre parênteses todo o conhecimento prévio acerca do fenômeno, ou: por em suspensão toda a noesis acerca do fenômeno, e somente recorrer ao que é noesis, se necessário, após.

Quer dizer: deve-se criar uma época para noesis após examinar longamente o fenômeno tal como ele se mostra.

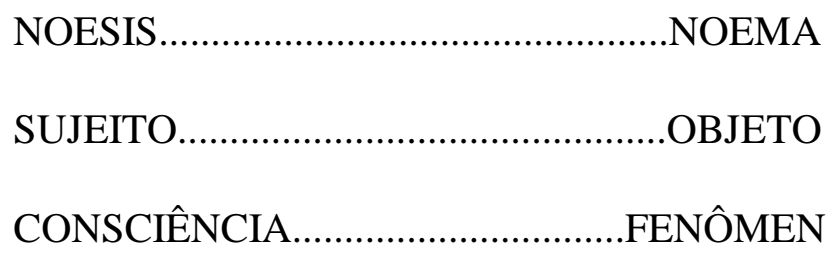

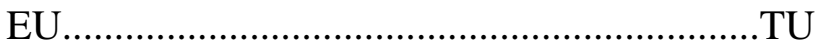

A tese de Sartre é a diferença entre o mundo das coisas "o ser", e a consciência "o nada". O ser é resistente, opaco, viscoso, ele é o "em si", a objetividade nua e bruta. O nada, ao contrário é a consciência, que é insubstancial, pura atividade e espontaneidade, é o "para $\mathrm{si}^{\prime}$.

A consciência somente é consciência quando consciência de alguma coisa, ou seja, a consciência não tem existência própria, ela não é um recipiente que armazena coisas, e só existirá quando houver intencionalidade, porque a consciência é um movimento e não algo concreto como na tradição cartesiana.

O EU (ego) só existe no homem (consciência para-si) quando ele se move em direção aos objetos. Transcender quer dizer movimentar-se. Esse movimento egóico faz com que o indivíduo viva enquanto ser para-si. E esse ego só se revelaria essência enquanto ausência de transcendência e intencionalidade. 
Não devemos confundir a abordagem de consciência feita neste trabalho com a consciência enquanto função psíquica, alvo inclusive de avaliações neuropsiquiátricas que investigam, entre outras coisas, a capacidade de o paciente captar o ambiente e orientar-se de forma lúcida e adequada. A consciência, considerada assim, é um processo de coordenação e síntese da atividade psíquica, o todo momentâneo que possibilita que se tome conhecimento da realidade naquele instante.

É uma função a partir da qual estabelecemos contato com a realidade e tomamos conhecimento direto e imediato dos fenômenos que nos cercam. E é claro que a dependência química prejudica profundamente essa função, inclusive com destruição gradativa das células nervosas.

O para-si é o ser consciente e transcendente, nele não há essência pois é um eterno incompleto que se completa e se descompleta continuamente. Nunca está pronto. Já a criança é considerada um ser-em-si que evolui ao para-si, pois a consciência da criança, estando em formação, transita entre o em-si e o para-si. Por exemplo, aos quatro meses de vida, aos dois anos e depois aos quatro anos, encontram-se em diferentes estágios do "em-si”.

Em relação ao para-si a consciência é tida como um "nada", em função de não haver interioridade (conteúdo) na consciência. O para-si e o em-si acham-se reunidos em uma conexão sintética que nada mais é do que o próprio para-si.

Com efeito, o para-si não constitui senão a pura nadificação do em-si; é como um buraco de ser no âmago do Ser. Portanto, o homem busca o "em-si” mas não o alcança.

A droga às vezes surge como tentativa de suprimento dessa impossibilidade de essência. A falta de essência do para-si significa falta de certezas e excesso de ansiedade. A ansiedade da falta.

Assim, há pessoas que vivem a ilusão de que possuem tudo e que nada lhes falta. Todavia, sendo a falta algo existencial e imanente, quando dela se tem consciência, no lugar de possibilidade se torna desespero.

A fama, por exemplo, pode criar graves problemas existenciais, porque o "ter" remete ao em-si, mundo das coisas, e nelas o ser jamais encontrará completude, uma vez que a relação com as coisas não cria correspondência de consciência. Então o simples fato de se possuir coisas, ou fama, não pode criar sentido à existência.

Entre os temas humanos o amor é um dos mais densos e complicados,e também nossa maior necessidade existencial: Receber e dar amor. Por causa de tanta densidade, a psicologia existencial foca o amor com interesse e intensidade.

Sabemos que o amor do para-si é complexo porque amar é dar, mas ainda que entendamos assim nem sempre queremos dar o que o outro espera, mas sim o que precisamos dar, ou o que entendemos que o outro deva receber. $\mathrm{O}$ amor é complexo porque entendo o meu dar também como uma forma de receber. Às vezes fantasio que o outro precisa ser como sou, e esperar o que espero e desejar o que desejo.

Muitas vezes pensamos que a prova do amor do outro é tornar-se como sou, ser uma extensão de mim, mesmo que deixe de ser ele mesmo. Acaba que o ápice do amor tornase o fato de eu receber do outro o que preciso receber enquanto dou o que preciso dar. É complexo, é a ação do para-si, um ser que é o que não é. Já o em-si é o que é. E jamais deixará de sê-lo. São considerações iniciais necessárias à compreensão da dinâmica 
ontológico e funcional dos sentimentos do ser quando se encontra no nível para-si, quando entra nessa condição impossível de permanecer, e quando retorna ao para-si que é a condição ontológica genuína do ser da consciência.

A pergunta que não quer calar é: se minhas escolhas são intencionais, se meus atos são atos de liberdade, onde ficam as ações e reações condizentes com a situação de trauma? Não existem traumas?

O trauma é um acontecimento intenso na vida de um sujeito incapaz de reagir a esse acontecimento de forma adequada. Trata-se de um excessivo afluxo de excitações que o sujeito não é capaz de tolerar e elaborar psiquicamente.

Pois bem, essa incapacidade aludida no conceito se desfaz com a maturidade. Se por algum motivo (e aqui não importa o motivo uma vez que não investigamos causalidade) não amadureço, tento o tempo todo permanecer na condição em-si. E aí o que importa não é o trauma, mas a permanência na condição em-si de um ser para-si. Isto pode ser má-fé, mas também pode ser uma patologia.

Se a terapia, acompanhada ou não de um tratamento medicamentoso for capaz de desfazer o trauma ou as consequiências comportamentais do trauma é porque operou na esfera da escolha. Se nenhum tratamento for capaz disso, estamos diante de um ser emsi e o trauma nessa investigação já não mais importa.

\section{Drogadicção: explicar ou compreender?}

Por mais que se tente explicar a causa da drogadicção em um sujeito sempre ficará faltando a questão do sentido, ou seja, a questão eminentemente humana. E sentido e significado não se explicam, podemos apenas tentar compreendê-los. Assim, o evento psicológico não pode ser explicado, apenas compreendido, pois teria um caráter de singularidade e sentido que não é captado por qualquer tipo de tentativa explicativoexperimental. Dilthey enfatiza sua crítica do caráter mutilador da abordagem explicativa, que perde o que os fenômenos humanos têm de específico, seu significado.

O processo de análise existencial do sujeito drogadicto não visa explicar a drogadicção, mas compreender o sujeito que faz da drogadicção o seu modo de existir. Explicar seria tentar descobrir de onde a drogadicção veio, compreender é tentar saber para onde ela vai. Compreender é investigar o "sentido" da drogadicção, ou seja, que papel ela ocupa na existência desse sujeito. Focando a pessoa e não a patologia.

Enfim, para que me "anestesio"? Para estar drogado? Para me dar essa aventura? Quero estar aventureiro ao preço da minha própria saúde e vida? Sim, escolho a via da aventura arriscando a minha vida. Então, que sentido (valor) dou à minha existência já que dela não cuido, a ela não preservo, e provavelmente não a amo? São perguntas que certamente nos ajudam a compreender uma existência com drogas.

Fundamental, para concluirmos a visão fenomenologico-existencial da drogadicção que entendamos um dos sentidos do conceito "ipseidade", porque quando o sujeito usa drogas ou faz qualquer outra coisa, ele lança mão do seu potencial de consciência intencional e se move em busca do preenchimento de uma falta. E a ipseidade designa a singularidade da coisa individual.

Explicando melhor: o para-si é integralmente ipseidade naquilo que determina o homem como não sendo o que é e sendo o que não é. Ou seja, não sou o que sou porque sou o 
meu projeto, e ao mesmo tempo sou o que não sou porque sou o meu projeto. Esta é a ipseidade (singularidade) do ser. O circuito de ipseidade se explica assim: O EU é um em-si com o qual a consciência se relaciona. O EU é $J E$ e $M O I$. Je, na condição préreflexiva e Moi na condição reflexiva. Porque o Ego (em-si - Je) é anterior à transcendência e O Ego (para-si - Moi) é transcendente. Uma vez lançado ao mundo, o homem transcende, se movimenta, faz vicejar sua existência consciente e intencional, enquanto para-si. E esse movimento existencial é fundamentado em liberdade, responsabilidade e consciência de intersubjetividade, propiciando que o homem escolha o seu próprio caminho e cresça com suas próprias experiências, assumindo a responsabilidade diante das consequências das suas próprias escolhas. Consciência de intersubjetividade porque o homem é um ser-no-mundo, e se por um lado somos livres, por outro não vivemos sem o mundo das coisas, das pessoas, das leis e das relações às quais estamos atrelados.

\section{Conclusão}

$\mathrm{Na}$ visão existencial, certas tendências como piedade, moralismo e paternalismo são desestimuladas uma vez que entendemos que cada pessoa tem o seu tempo, o seu jeito, o seu caminho. E ninguém pode ser modelo existencial para o outro.

Usar drogas, mesmo como ação de liberdade e subjetividade, deve levar em conta o interesse social. À medida que esta prática gera risco social, tal comportamento deixa de ser uma ação de responsabilidade exclusivamente individual. Mesmo o drogadicto tem a responsabilidade de pensar e repensar suas escolhas. Criticá-las. Talvez a terapia existencial na drogadicção tenha como principal papel ajudar o indivíduo a pensar criticamente suas escolhas e ações.

Às vezes pensamos o dependente químico como alguém incapaz de avaliar, criticar suas escolhas e se responsabilizar por elas. Consideramos que se ele deseja afundar-se nas drogas, isto é uma escolha. Pode ser desagradável, podemos discordar, desaconselhar, mas é uma escolha subjetiva e ele precisa responsabilizar-se e ser responsabilizado por ela. Se o drogar-se é uma tentativa de entrar na condição em-si, se tratarmos o dependente químico como um ser-em-si, e isto fazemos dando proteção excessiva e consertando o tempo todo os erros dele, o que estamos fazendo é fortalecer essa atitude de irresponsabilidade e má-fé.

E tal atitude, além de atrasar sua recuperação, é, em si mesma, inútil. Temos por certo que, muitas vezes, conseguimos defender uma pessoa de outras pessoas, mas, dificilmente, conseguimos proteger uma pessoa dela mesma, já que nem sempre é possível impedir que uma pessoa faça mal a si própria. Então precisamos aprender a respeitar a subjetividade permitindo que as pessoas escolham com liberdade, se responsabilizem por suas escolhas e cresçam com suas próprias experiências.

Sartre disse:

São os nossos atos que nos definem. Nós mesmos desenhamos nosso próprio retrato e não há nada além desse retrato. Nossas ilusões e imaginações a nosso próprio respeito e sobre o que poderíamos ter sido são decepções auto-infligidas acerca do que 
não quisemos fazer dentro das nossas possibilidades, que não são poucas.

Nossa identidade é formada, reformada, transformada ao longo da nossa existência. Quem sou é uma pergunta que respondo todos os dias. Hoje a droga pode ser base de identidade e identificação de uma pessoa, mas amanhã pode não ser mais.

O conceito de liberdade fundamenta a visão fenomenologico-existencial da drogadicção, lembrando que "não há liberdade sem responsabilidade", já que o homem é homem por sua condição de ser livre. E se constitui afirmando suas escolhas livres. É produto de sua liberdade, pois na ação livre ele escolhe seu ser e se constrói enquanto sujeito.

Assim, toda ação, escolha ou objetivo de vida, são produtos da Liberdade,que deixa de ser uma conquista humana, para, ser uma condição da existência humana, como já vimos anteriormente.

Fortalecemos o drogadicto acentuando sua responsabilidade e não sua dependência, porque nunca uma tempestade parou por causa de uma rosa frágil.

E uma importante sinalização da psicologia existencial é que mais do "livres de", somos "livres para". E isto significa que o melhor sentido de liberdade é LIBERTAÇÃO. Lembrando que o contrário da dependência não é a abstinência e sim a liberdade.

\section{Referências}

HUSSERL, Edmund. Idéias para uma fenomenologia pura e para uma filosofia fenomenológica. Aparecida, SP: Idéias \& Letras, 2006.

SARTRE, Jean-Paul. O ser e o nada. Petrópolis: Vozes, 1999.

MONTEIRO, Walmir. O tratamento psicossocial das dependências. Belo Horizonte: UNI-BH, Editora Milênio, 2000. 